\title{
Physical and mechanical properties of aluminum dross
}

\author{
Samson Oluropo Adeosun*, Olatunde Israel Sekunowo, Omotayo Oluwaseyi Taiwo, \\ Wasiu Ajibola Ayoola, Adebowale Machado
}

Department of Metallurgical and Materials Engineering, University of Lagos 101001, Nigeria

\section{Email address:}

samsonoluropo@yahoo.com (S. O. Adeosun),olatundeisrael@yahoo.co.uk (O. I. Sekunowo), taiwooluwaseyi2003@yahoo.com (O. O. Taiwo),wayoola@unilag.edu.ng (W. A. Ayoola), machadomunirat@yahoo.com (A. Machado)

\section{To cite this article:}

Samson Oluropo Adeosun, Olatunde Israel Sekunowo, Omotayo Oluwaseyi Taiwo, Wasiu Ajibola Ayoola, Adebowale Machado. Physical and Mechanical Properties of Aluminum Dross. Advances in Materials. Vol. 3, No. 2, 2014, pp. 6-10.

doi: 10.11648/j.am.20140302.11

\begin{abstract}
The study on the physio-mechanical behavior of aluminum dross has been carried out. The amount of aluminum dross used varied between 50 and $90 \mathrm{wt} \%$, while bentonite added to the dross varied from $10-50 \mathrm{wt} \%$ with a fixed amount of water. Using dross particle sizes of $106 \mu \mathrm{m}$ and $184 \mu \mathrm{m}, 10$ samples are produced from each particle size. The bricks are dried in still air for $24 \mathrm{hrs}$ at $31^{\circ} \mathrm{C}$, oven drying at $110^{\circ} \mathrm{C}$ for $24 \mathrm{hrs}$ and sintered at $450^{\circ} \mathrm{C}$ for $8 \mathrm{hrs}$. The bricks characteristics in terms of volume shrinkage, apparent porosity, bulk density, cold crush strengths and permeability are then evaluated. The results show that the $106 \mu \mathrm{m}$ particle size dross brick has the highest volume shrinkage of $24 \%$, apparent porosity of $15 \%$ and peak bulk density of $1.9 \mathrm{~g} / \mathrm{c}$.c. However, the dross brick exhibits relatively low cold crush strength of $940 \mathrm{KN} / \mathrm{m}^{2}$. The $106 \mu \mathrm{m}$ size bricks demonstrate a minimum of $85 \%$ permeability compared with $70 \mathrm{wt} \%$ of $184 \mu \mathrm{m}$ bricks which may be due to variation in dross particles agglomeration. Given these results, the $106 \mu \mathrm{m}$ particle size brick can serve as acid refractory because its properties compared well with medium-alumina fireclay.
\end{abstract}

Keywords: Aluminum Dross, Bricks, Bentonite, Physio-Mechanical Properties

\section{Introduction}

Aluminum dross is one of the waste products obtained during aluminum refining. It consists of metal, salts oxides, and other non metallic substances. Basically, aluminum dross is classified as either black or white while the black (dry) dross has low metal content with high amounts of oxides, salts and granular-like in form similar to sand. The white (wet) dross has extremely high metal content with small amounts of oxides and salts and form large clumps or blocks. Aluminum dross is usually produced from the melting of aluminum scrap such as used beverage containers, aluminum siding, castings and the treating of the melt with salt flux. The salt flux accumulates on top of the melt and forms dross or skim which contains aluminum and other elements such as magnesium, silicon and others in trace amount.

The safe disposal of aluminum dross as a waste is a burden to Aluminum manufacturing companies because its improper disposal affects the eco-system, surface and ground water. When these dross particles are allowed to escape into the atmosphere, inhalation can cause health problems such as Alzeheimer's disease, silicosis and bronchitis [1-4]. However, dross product is not entirely a waste material as it can be recycled and used in secondary steelmaking for slag deoxidation [5]. Approximately, four million tonnes of white dross and more than a million tonnes of black dross are reported throughout the world each year, and around $95 \%$ of this material is land-filled $[6,7]$. In the UK it is reported that the industry disposes about 200,000 tonnes of white and black dross [6, 7]. The quantities of dross land filled nowadays are expected to be lower, as a large chunk of it is being reprocessed to recover metallic aluminum as well as its oxides. Similarly, the utilization of this material as filler in asphalt may improve stiffness and it is thought that could also improve abrasion resistance and control micro-cracking [8]. The potential use of dross (as filler) in concrete products such as, non-aerated concrete, concrete bricks and concrete roof tiles has being investigated by [7]. According to [10, 11], the non-metallic residues produced during processing of aluminum dross could be used as a source of aluminum oxide in cement's recipe. In such instance, only the part adjudged to be of insignificant commercial value is declared as process waste 
as a direct release of the dross to the environment as waste can have adverse impact on the eco-systems [9].

It is envisaged that the process of recovery of useful metallic and non-metallic residues will add to the cost of operation and will demand the application of a new technology or the adaptation of an existing one which may not be without a cost. However the conversion of the dross to refractory material will add value to the dross and convert waste to wealth. This paper thus presents the results of physical and mechanical properties of aluminum dross as potential acid refractory material suitable for use in furnaces.

\section{Experimental Methodology}

The Aluminum dross used in this study is obtained from Aluminum Rolling Mills, Ota in Nigeria, and its chemical composition shown in Table1. The lump aluminum dross is crushed and sieved into $106 \mu \mathrm{m}$ and $184 \mu \mathrm{m}$.. Measured amounts of aluminum dross, bentonite and water for brick mixes are done using electronic digital weighing scale. The lump dross is shown in Fig. 1. The weighed aluminum dross ranged from 50-90 wt \% and each mixed contain 10 $50 \mathrm{wt} \%$ bentonite mixed with 6.25 litres $(50 \mathrm{~g})$ of water. Each mix is poured into a mould and rammed in a standard ramming machine. The procedure is repeated to produce ten brick samples from each dross particle size. All samples produced are dried in still air at $31^{\circ} \mathrm{C}$ for $24 \mathrm{hrs}$.

Table 1. Chemical Composition of Aluminum dross.

\begin{tabular}{cccccccccc}
\hline Element & $\mathrm{SiO}_{2}$ & $\mathrm{CaO}$ & $\mathrm{Na}_{2} \mathrm{O}$ & $\mathrm{Al}_{2} \mathrm{O}_{3}$ & $\mathrm{Fe}_{2} \mathrm{O}_{3}$ & $\mathrm{MgO}$ & $\mathrm{SO}_{3}$ & $\mathrm{~K}_{2} \mathrm{O}$ & $\mathbf{A l}$ \\
\hline $\begin{array}{c}\text { Compositio } \\
\text { n } \%\end{array}$ & 7.15 & 0.07 & 0.06 & 63.84 & 0.03 & 0.04 & 0.03 & 0.01 & 28.77 \\
\hline
\end{tabular}

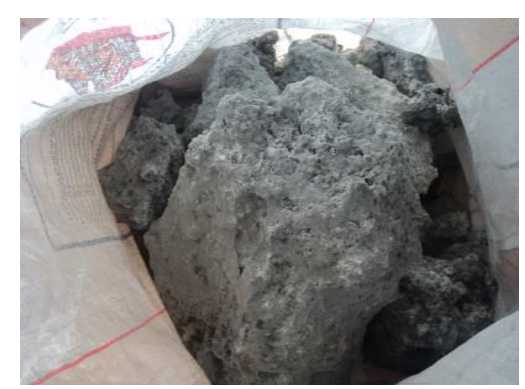

Fig 1. Lump dross.

\subsection{Apparent Porosity and Bulk Density}

The hot test piece boiling water method is used. The brick specimen is dried in an oven at $110^{\circ} \mathrm{C}$ to a constant weight (D) and then suspended in distilled water, boiled in water for $2 \mathrm{hrs}$ and subsequently cooled to room temperature $\left(31^{\circ} \mathrm{C}\right)$ while its weight $(\mathrm{S})$ is noted. The heated brick specimen is then cleaned of water using light blotting with a wet towel and thereafter weighed in air (W). The brick's apparent porosity and bulk density are calculated as in equations 1 and 2 respectively.

$$
\mathrm{P}_{(\mathrm{app})}=\frac{W-\Sigma}{W-\Sigma} \times 100(\%)
$$

Where $\mathrm{W}-\mathrm{D}=$ actual volume of open pores of the specimen, $\mathrm{W}-\mathrm{S}=$ external volume of the specimen

Bulk density is calculated as,

$$
\text { Bulk density }=\frac{D}{w-s}\left(g / \mathrm{cm}^{3}\right)
$$

\subsection{Volume Shrinkage}

For this test, brick specimens of dimension $39.5 \mathrm{~mm} \mathrm{X}$ $70 \mathrm{~mm}$ are made in green form. The initial lengths of the specimens are measured with vernier calipers, air-dried for $24 \mathrm{hrs}$ and oven dried at $110^{\circ} \mathrm{C}$ for $24 \mathrm{hrs}$ after which the final lengths are determined to give the dried lengths. The specimens are further fired at $450^{\circ} \mathrm{C}$ for $8 \mathrm{hrs}$, cooled to room temperature $\left(31^{\circ} \mathrm{C}\right)$ and the fired lengths measured again. The fired shrinkage is determined as in equation 3.

$$
\% \text { of fired shrinkage }=\left(V_{D}-V_{F}\right) / V_{D} \text { X 100\%, }
$$

Where $\mathrm{V}_{\mathrm{D}}=$ dried volume and $\mathrm{V}_{\mathrm{F}}=$ fired volume

\subsection{Cold Crushing Strength}

The dross test bricks are placed one after the other on a compressive hydraulic strength testing machine using an applied load at a rate of $20 \mathrm{KN} /$ minute (see Fig. 1c). The crushing strength is calculated using equation 4 .

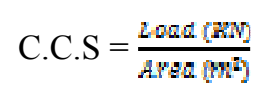

\subsection{Permeability to Air}

Test samples are air dried for $24 \mathrm{hrs}$ and further dried at $110^{\circ} \mathrm{C}$ for $12 \mathrm{hrs}$ in an oven. The permeability-testing machine consisted of a cylindrical arrangement in which a bell jar is put in place to displace certain volume of air, which is equal to the volume of water placed in the cylinder. A manometer is connected to measure the pressure during the displacement of air. The samples are completely scaled on the sides and the lower surface is exposed to an orifice. The cylinder is filled with $200 \mathrm{~cm}^{3}$ of water and the bell jar is put in place. The Orifice is opened and time taken for $2000 \mathrm{~cm}^{3}$ of water to displace equal volume of air through the samples is taken. The pressure difference between the surfaces is measured by the manometer and the test piece permeability determined using equation 5 .

$$
\mathrm{PA}=\mathrm{VA} / \mathrm{APT}
$$

$\mathrm{PA}=$ Permeability to air, $\mathrm{cm}^{3} / \mathrm{min}, \mathrm{V}=$ Volume of air displaced, $\mathrm{cm}^{3}, \mathrm{H}=$ Height of specimen, $\mathrm{cm}, \mathrm{A}=$ Cross -

Sectional area of specimen, $\mathrm{cm}^{3}, \mathrm{~T}=$ time taken, $\mathrm{min}, \mathrm{P}=$ Pressure of air, $\mathrm{cm}$ of $\mathrm{H}_{2} \mathrm{O}$.

\section{Results and Discussion}

\subsection{Volume Shrinkage}

In Fig. 2, the volume shrinkage behavior of the aluminum dross bricks is shown. The volume shrinkage 
decreases as the percentage of bentonite in the brick decreases from 50-10 wt \%, but increases as aluminum dross content. The fine particle $(106 \mu \mathrm{m})$ aluminum dross bricks show high shrinkage of $16-26 \%$ at $50-80 \mathrm{wt} \%$ dross content. The $184 \mu \mathrm{m}$ bricks show low shrinkage reduction of $16-10 \%$ from $50-90 \mathrm{wt} \%$ dross content. The behavior of the bricks can be explained in relation to the structural changes that occur in response to thermal treatment.

Large particles of dross have air-pores space between it particles and these spaces are eliminated during firing while the gaseous medium in the pores are sacrificed in the firing process. However, for fine particles where these pores are evidently very small, interlock gaseous medium between the matrix and the binder are involved in an expansion which decreases with binder content. This arises from the fact that bentonite is hydrophilic and the more of it, the higher the water content of the mix.

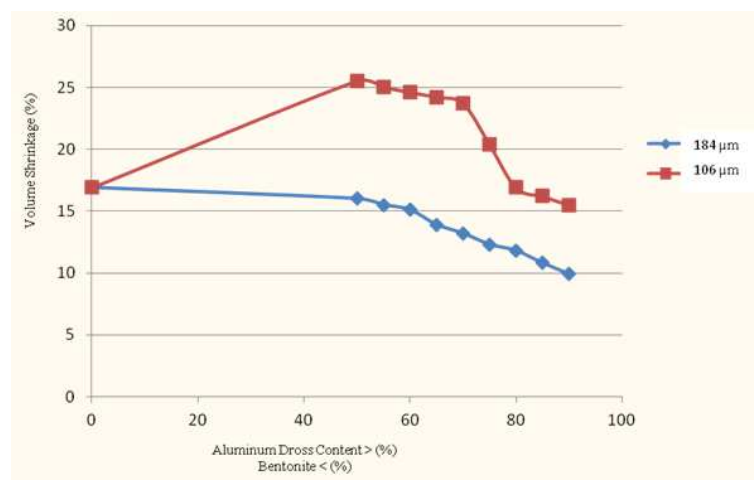

Fig 2. Variation of dross-brick Volume Shrinkage at different dross particle size.

\subsection{Apparent Porosity (AP)}

Fig. 3 depicts the apparent porosity variation of the bricks at different dross particle sizes. The apparent porosity (AP) of $106 \mu \mathrm{m}$ and $184 \mu \mathrm{m}$ sized bricks decreases linearly as the bentonite content decreases with the peak AP of $106 \mu \mathrm{m}$ brick being at $50 \mathrm{wt} \%$ bentonite content. For low porosity bricks requirement, the $184 \mu \mathrm{m}$ size brick will be preferred.

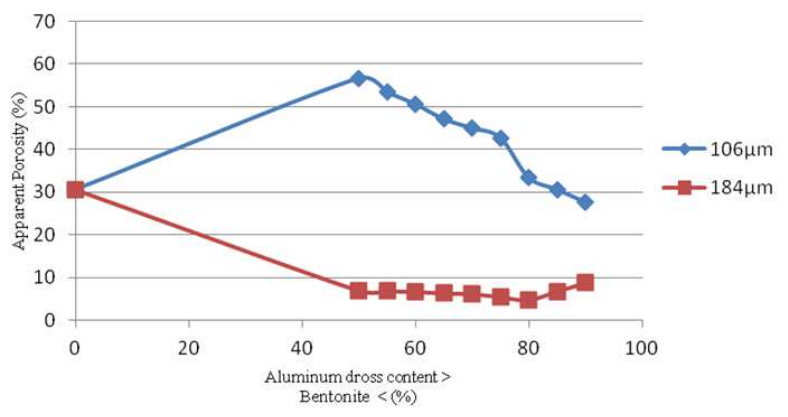

Fig 3. Apparent porosity of Aluminum dross brick.

\subsection{Bulk Density}

As illustrated in Fig 4, the bulk densities of the bricks decrease from $2.2 \mathrm{~g} / \mathrm{c}$.c. for $100 \mathrm{wt} \%$ of bentonite brick as binder in bricks decreases. The $106 \mu \mathrm{m}$ sized bricks have peak bulk density of $1.9 \mathrm{~g} / \mathrm{c} . \mathrm{c}$ at $30-40 \mathrm{wt} \%$ binder and at $10 \mathrm{wt} \%$ binder it is $1.8 \mathrm{~g} / \mathrm{c}$.c. In the range of bentonite used the bricks bulk densities lies within 1.8-2 g/c.c. for both $106 \mu \mathrm{m}$ and $184 \mu \mathrm{m}$ particle size bricks.

At higher density, water of hydration could be present at the surfaces of inorganic fillers conferring high tendency to agglomerate. Agglomeration of particles may cause pockets of air between particles leading to increase in density of a composite material. At lower density, however, there is the tendency of enhanced filler-matrix compatibility as the matrix displaced the trapped air pockets. This could produce de-agglomeration of the particles with improved filler dispersion [12]. In comparism, however, it is observed that the bulk densities of the aluminum dross is inferior to that of pure bentonite even as bentonite addition declines to $10 \mathrm{wt} \%$

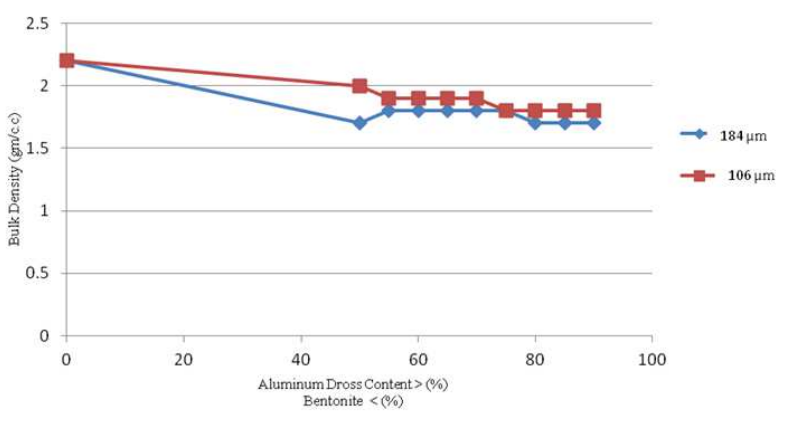

Fig 4. Bulk Density of Aluminum dross brick.

\subsection{Cold Crush Strength.}

The cold crush strengths of $50 \mathrm{wt} \%$ bentonite addition to aluminum dross bricks are $940 \mathrm{KPa}$ and $100 \mathrm{KPa}$ for $106 \mu \mathrm{m}$ and $184 \mu \mathrm{m}$ sized particles respectively (see Fig. 5). This demonstrates a steady decrease with decrease in binder content. The size of pores between particles, particle size and possible particle agglomeration are likely factors that may have affected the cold crushing strengths of the bricks. In particular, the $184 \mu \mathrm{m}$ size bricks show very low C.C.S as binder content declines. This also may be attributed to the size of pores between particles compared to that of $106 \mu \mathrm{m}$ size bricks.

The decline in strength in composite samples as aluminum dross content increases from $50 \mathrm{wt} \%$ over the matrix can be attributed to poor interfacial adhesion between the hydrophilic binder and the hydrophobic matrix which hinders proper load transfer between binder and matrix. Further, smaller size binder confers superior strength due to larger surface area which gives rise to better adhesion with matrix coupled with better distribution of particles within the matrix [13]. Similarly, the size and dispersion of binder particles in the matrix can affect the composite properties. This agrees with [14] to the effect that small, well-dispersed particles generally give better properties. This is, because, small particles can block crack propagation, resulting in impact toughening. However, it is 
often difficult to disperse very fine particles due to their tendency to agglomerate.

Thus, the initial increase in strength of the aluminum dross is due to good binder -matrix interactions and according to [15] enables more stress to be transferred from the matrix to the fillers during external loading.

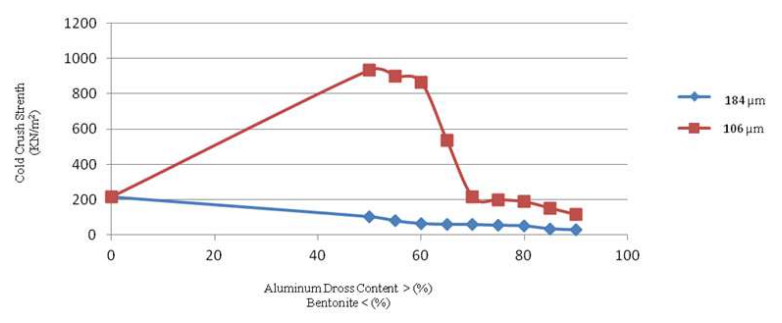

Fig 5. Cold Crush Strength of Aluminum dross brick.

\subsection{Permeability}

The permeability responses of the aluminum dross bricks is shown in Fig. 6 . The $106 \mu \mathrm{m}$ sized bricks demonstrate a reverse cosine pattern with the minimum permeability of $85 \%$ at $70 \mathrm{wt} \%$ dross and two peaks at $50 \mathrm{wt} \%(115 \%)$ and $90 \mathrm{wt} \%(125 \%)$ dross content. In contrast, the $184 \mu \mathrm{m}$ bricks show a sinusoidal pattern falling from $135 \%$ at 40 wt $\%$ bentonite to $70 \%$ at $60 \mathrm{wt} \%$ dross. It also rose with increase in aluminum dross contents and decline to $70 \%$ at $90 \mathrm{wt} \%$ aluminum. The initial decrease in permeability could be attributed to particles agglomeration in the $106 \mu \mathrm{m}$ while the $184 \mu \mathrm{m}$ particles expansion and blockage of the gaseous pores during firing could promote this phenomenon. With more of the fine particles of dross, deagglomeration can occur and in large particles more gaseous pores are formed. These will activate increase permeability in both cases.

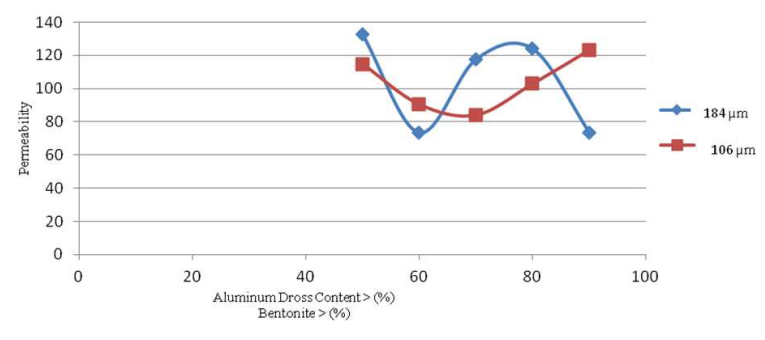

Fig 6. Permeability of Aluminum dross brick.

\section{Conclusion}

The physical and mechanical properties of aluminum dross have been studied .The dross brick made from $106 \mu \mathrm{m}$ sized particles have optimum properties of $29.8 \%$ volume shrinkage, low apparent porosity of $15 \%$ and bulk density of $1.9 \mathrm{~g} / \mathrm{c}$.c. This implies that good refractory brick can be produced with this particle size. Given this level of performances, aluminum dross bricks possess properties which compared well with medium-alumina fireclay in terms of volume shrinkage-30\%, apparent porosity- $22.1 \%$ and bulk density- $1.97 \mathrm{~g} / \mathrm{c} . c$. Thus this hazardous industrial waste can be employed in refractory brick production suitable for acid slag. However, the cold crush strength of this brick is inferior to medium-alumina fireclay brick.

\section{References}

[1] M. F. A. Berkum and D. R. C.McLachlan, Aluminum: a role in degenerative brain disease associated with neurofibrillary degeneration, Progress in Brain Research, vol. 70, (1986), pp. 399-410.

[2] R. A. Goyer, Toxic Effects of Metals, in: M. O. Amdur, J. Doull, and C. D. Klassen (Eds.), Casarett \& Doull's Toxicology, The Basic Science of Poisons, , Permogen Press, 4th edition, 1991, pp. 622-6663.

[3] D. Shore and R. J.Wyatt, Aluminumand Alzheimer's disease, Journal of Nervous And Mental Disease, vol. 171, no. 9, (1983), pp. 553-558,.

[4] A. I. Arieff, J. D. Cooper, D. Armstrong, and V. C. Lazarowitz, Dementia, renal failure, and brain aluminum, Annals of Internal Medicine, vol. 90, no. 5, (1979) pp. 741747.

[5] K.J. Elzea, T.C. Nikhil, M.B James, T.K. Stanley, Industrial Minerals and rocks: Commodities, Markets and uses (7th ed.), Society for Mining, Metallurgy and Exploration (SME), 2006, p. 1406 .

[6] O. Hollins. Aluminum industry could dramatically reduce land filling of furnace waste. URL $<$ http://www.ohlsti.co.uk/ohl/newsletter/ohl_wmr312.pdf >. (accessed November 11, 2007).

[7] Brough, M. (2002): Aluminum Lightens the Environmental Load. Vision-The newsletter of the Foresight and Link Initiative.

Winter,URLhttp://www.berr.gov.uk/files/file30193.pdf (accessed November 11, 2007).

[8] A.M.Dunster, ,F. Moulinier, B. Abbott, A. Conroy, K. Adams, D. Widyatmoko, Added value of using new industrial waste streams as secondary aggregates in both concrete and asphalt". Aggregates Research Programme STBF 13/15C. The Waste and Resources Action Programme. 2005.

[9] Mukhopadhyay, Y.V. Ramana, S. Upendra, The Minerals, Metals \& Materials Society Jawaharlal Nehru Aluminum Research development and Design Centre Light Metals, 2004.

[10] M. C. Shinzato \& R. Hypolito, Solid waste from aluminum recycling process: Characterization and reuse of its economically valuable constituents. Waste Management, 25, 2005, pp. 37-46.

[11] Pickens, J. W. \& Morris, E. L.: Process for preparing calcium aluminate from aluminium dross, In Office, U. S. P. T.O. (Ed.) US Patent No: 6238633, (2001).

[12] Y.W.Leong, M.B. Abubakar, Z.A Mohdishaka, A. Ariffin, Effects of Filler Treatments on the Mechanical, Flow, Thermal and Morpholical Properties of Talc and Calcium Carbonate filled Polypropylene Hybrid Composites, Journal of Applied Polymer Science, Vol. 98, (2005), pp. 413-426. 
[13] H.S. Yang, H.J. Kim, J. Son, H.J. Park, B.J. Lee and T.S. Hwang, Rice Husk Filled Polypropylene Composites; Mechanical and Morphological Study composite Structures. 63, (2004) pp.305-312.

[14] T. Inoue, and T.Suzuki, Selective Cross linking Reaction in Polymer Blends - The Effects of the Cross linking of Dispersed EPDM in Particles on the Impact Behaviour of
PP/EPDM Blends, Journal of Applied Polymer Science, 56, (1995), pg. 1113.

[15] C. Andrzej, K. Habermehl-Cwirzen, The effects of Carbon Nano and Micro fibres on strength and residual cumulative strain of mortars subjected to freeze-thaw circles". Journals of Advanced Concrete Technology. Vol 11 (2013), pp. 80-88. 